\title{
Valuable bioproducts obtained from microalgal biomass and their commercial applications: A review
}

\author{
Gatamaneni Loganathan Bhalamurugan ${ }^{\dagger}$, Orsat Valerie, Lefsrud Mark \\ Department of Bioresource Engineering, McGill University, MacDonald Campus, 21111 Lakeshore Road, Quebec, H9X 3V9, Canada
}

\begin{abstract}
Microalgae are likely to become a part of our everyday diet in the near future as they are considered to be rich in proteins, carbohydrates, and high density lipoproteins. They will play a pivotal role in the food cycle of many people around the globe. Use of microalgae in treating wastewater is also one of the disciplines which are luring researchers as this contributes to a sustainable way of exploiting resources while keeping the environment safe. In addition, microalgal biomass also has the potential to be used as a feedstock for producing biofuel, bio fertilizers, pharmaceuticals, nutraceuticals and other bio-based products. This review presents the different value-added products obtained from microalgal biomass and the applicability of these products commercially.
\end{abstract}

Keywords: Biomass, Microalgae, Sustainable, Wastewater

\section{Introduction}

Algae are commonly classified into microalgae and macroalgae depending on their cellular organization [1]. The organizational structure of microalgae defines them as being monocellular; hence they can only be identified using a microscope [2]. The first glimpse of microalgae was reported a long time ago, in oceans where they grew rapidly by utilizing the available carbon dioxide and converting it into oxygen by means of photosynthesis [3]. Classification of microalgae into prokaryotes or eukaryotes is mainly dependent on the organelles present. For instance, prokaryotes have no distinct nucleus whereas eukaryotes possess a distinct nucleus. Microalgae seem to rule both on land and water as they have exhibited the capability of surviving even in the harshest of environmental conditions [4]. Microalgae (Nostoc) was first utilized some 2,000 years back by the Chinese for surviving drought, however, it is only lately that innovative technologies using microalgae began to emerge [5]. Microalgae grow rapidly with small amounts of water and nutrients in comparison with other plants that grow on land. For instance, the amount of water required for producing $1 \mathrm{~kg}$ of algal biomass is 333 liters when compared to soy which requires 2,204 liters to produce the same amount [6, 7]. Another virtue of microalgae is its ability to grow on industrial wastewaters by using their excess nutrients, thereby rendering the wastewater environmentally safe with minimal water utilization. Besides this, microalgae can also sequester the excess carbon dioxide from the atmosphere and from flue gasses released by industries. Hence, microalgae have been considered as a sustainable feedstock for the bio-refinery industries of the future [8]. Microalgae also possess certain medicinal properties, as a function of their composition, which makes them potential candidates for manufacturing bio-based chemicals of pharmaceutical and nutraceutical interest. Cultivation of microalgae on a large scale for bio-diesel production was estimated to yield 20 times more bio-diesel than the traditional bio-diesel crops such as soya, rapeseed and jatropha [9]. The residual biomass obtained from microalgae, therefore, could be used as a potential feedstock for obtaining value-added products [10]. For algal technology to attain success, researchers should have a thorough understanding of algal species and their behavior under a variety of conditions in order to carefully choose specific strains based on the desired end products [11]. The following features make microalgae a source of attraction among researchers. First, microalgae can produce a range of value added products such as proteins, lipids, carbohydrates and pigments which can be enhanced under stressed environmental conditions [12]. Second, they have the ability to introduce stable isotopes into products that are manufactured
This is an Open Access article distributed under the terms of the Creative Commons Attribution Non-Commercial License (http://creativecommons.org/licenses/by-nc/3.0/) which permits unrestricted non-commercial use, distribution, and reproduction in any medium, provided the original work is properly cited.

Copyright (C) 2018 Korean Society of Environmental Engineers
Received December 27, 2017 Accepted February 6, 2018

${ }^{\dagger}$ Corresponding author

Email: bhalamurugan.gatamaneniloganatha@mail.mcgill.ca Tel: +1-514-231-9174

ORCID: 0000-0003-4043-0489 
from them. Third, only a few numbers of species have been identified till date making it an interesting domain to be explored, even today [5]. However, the downstream processing involved in producing these value-added products is high. One of the ways for reducing the cost is to derive multiple products in a single cycle (Biorefinery concept) [12]. According to an article published by "Business Insider", it is believed that by 2025, products obtained from microalgae could be produced on a larger scale and in an environmental friendly manner [13]. The current review underlines how the biomass produced from microalgae has been successfully employed for the sourcing of a variety of value added products.

\section{Value-added Products Obtained from Microalgae}

The most predominant research that surrounds algae is targeting the production of biofuels, however, the process remains costly and this makes it economically non-feasible [14]. Nonetheless, there has been a recent shift in the trend of using microalgae for the production of value-added compounds. A lot of high-value products have already been identified and marketed, however, with the emergence of newer algal growth technologies there is always a possibility of discovering additional products which are of high economic value [15]. Some of the most commonly produced value-added products obtained from microalgae are listed below.

\subsection{Lutein}

The carotenoid lutein is predominantly found in almost all fruits and vegetables. However, the most important sources of lutein ingested by humans are from maize and egg yolk [16]. Most of the lutein produced commercially is extracted from the petals of the marigold flower. In parallel, microalgae are gaining importance because they show higher productivities of lutein production when compared to the marigold cultivars. Furthermore, the land area and labor involved for cultivating microalgae are less when compared to the cultivation of marigolds [17]. The amount of lutein produced by microalgae depends on various environmental conditions like temperature, $\mathrm{pH}$, irradiance, salinity and the quantity of available nitrogen [18]. The microalgae commonly used for producing lutein include Muriellopsis sp., Scenedesmus almeriensis, Chlorella protothecoides, Chlorella zofingiensis, Chlorococcum citriforme, and Neospongiococcus gelatinosum [17]. For instance, the amount of lutein produced from the microalga Scenedesmus almeriensis was $4.77 \mathrm{mg} / \mathrm{L} / \mathrm{d}$, with 1,000 mg of lutein from algae source costing approximately 2.5 US\$ $[19,20]$.

\subsection{Astaxanthin}

Astaxanthin is a carotenoid that belongs to the xanthophyll family and is deemed to be one of the high-value products available in the market today. Astaxanthin acts as an antioxidant and also serves to protect the skin from ultraviolet radiations. The production cost of synthetic astaxanthin is considered to be lower than that obtained from microalgae. This constitutes the greatest drawback for harnessing microalgae in the production of astaxanthin. However, certain microalgae like Haematococcus pluvialis [21] and Chlorella zofingiensis [18] have been success- fully employed in producing astaxanthin commercially. For instance, Haematococcus pluvialis produced $35 \mathrm{mg} / \mathrm{g}$ of astaxanthin with an approximate market value of $1.8 \mathrm{US} \$$ for $1,000 \mathrm{mg}$ of astaxanthin [21-23].

\section{3. $\beta$-carotene}

One of the vital carotenoids, $\beta$-carotene has been used in industry as a coloring agent, as an antioxidant, and as a vitamin-A supplement. Besides this, it is also known to possess antiaging and anticancer properties. The main source of natural $\beta$-carotene is the carrot, however, algae have been considered as an alternate natural source for the production of $\beta$-carotene [24]. The most commonly used microalgae for production of $\beta$-carotene are Dunaliella salina ( $D$. salina), Scenedesmus almeriensis, and Dunaliella bardawil [18, 24]. For instance, the amount of $\beta$-carotene produced from Dunaliella bardawil was $1.65 \mathrm{pg} / \mathrm{cell}$ with an approximate market value of approximately 0.6 US\$ per $1,000 \mathrm{mg}$ of $\beta$-carotene [20, 24].

\subsection{Zeaxanthin}

Zeaxanthin is generally a yellow colored carotenoid and is typically found in corn, egg yolk, gul mohr, orange, berries, and marigold flowers. Zeaxanthin is mainly used in pharmaceutical, cosmetics and food industry applications [25]. The commonly used microalgae for the production of zeaxanthin are Scenedesmus almeriensis and Nannochloropsis oculata [26, 27]. The amount of zeaxanthin produced by Scenedesmus almeriensis was $0.34 \mathrm{mg} / \mathrm{g}$ with a market value of approximately 10 US\$ per 1,000 mg [26, 28].

\subsection{Docosahexaneoic Acid (DHA) and Eicosapentaneoic Acid (EPA)}

Polyunsaturated fatty acids (PUFAs) such as DHA and EPA have been known to impart good health for humans as part of healthy diets and healthy living. Fish oil, one of the major sources of DHA and EPA has been harnessed successfully and has reached its maximum worldwide production [29]. Environmental hazards are considered to be one of the reason for the limitation and decline in the commercial production of PUFA from fish sources, and hence alternate sources are being investigated [30]. Another problem of obtaining PUFA from fish is that the oil extracted has an unpleasant "fishy" odor [31]. Recently, microalgae have been employed in the production of oils rich in DHA and EPA and are now being increasingly used in the food industry. The most common algae employed for the production of DHA-rich algal oil include Schizochytrium, Ulkenia, Isochrysis galbana, Chlorella pyrenoidosa, Chlorella ellipsoidea and Crypthecodinium. The important microalgal growth factors affecting the production of DHA and EPA include temperature and salinity [29, 32].

\subsection{Lycopene}

Tomatoes are the major source of lycopene. It is considered to be one of the most influential antioxidants and cannot be produced by animals [33]. Lycopene is also considered to be an effective sunscreen agent [34]. Lycopene is known to have a great impact on human health as it possesses anticarcinogenic and antiatherogenic properties. Dietary intake of lycopene by 
humans, as an antioxidant, reduces the oxidative stress by trapping reactive oxygen species and thereby reduces the risk of chronic diseases like cancer and cardiovascular diseases [33]. An epidemiological study showed that the instance of prostate cancer was reduced with the consumption of foods rich in lycopene [35]. The yield of lycopene, as compared to $\beta$-carotene, obtained through chemical synthesis was poor ( $45 \%$ and $36 \%$, respectively); hence the discovery of an alternate sustainable way is required [36]. An in vivo study revealed that algal lycopene obtained from Chlorella marina exhibited higher antioxidant and anti-inflammatory effect in high cholesterol fed rats when compared to standard drug lovastatin and trans-lycopene produced from tomatoes [37]. Therefore, production of lycopene from microalgae should be explored and Blakeslea trispora, a fungal plant pathogen, is the only lycopene-producing micro-organism (156 mg - 578 mg yield of lycopene per liter through fermentation) that has reached commercial production till date [33, 36].

\subsection{Phycobiliproteins}

Phycobiliproteins are formed by bonding water soluble proteins with phycobilins or chromophores during photosynthesis [38]. Phycobiliproteins are coloured pigments that are mainly found in cyanobacteria and red algae. Based on the UV-Visible absorption spectra, four main classes of phycobiliproteins exist namely phycocyanin, allophycocyanin, phycoerythrin and phycoerythrocyanin [39]. The market value of phycocyanin alone reached between 5-10 million US\$ [40]. The major sources of phycobiliproteins include Spirulina sp., Arthrospira platensis, and Amphanizomenon floa-aquae. Phycobiliproteins are used commercially as natural dyes and fluorescent agents as well as used in pharmaceutical (antioxidant, anti-inflammatory, neuroprotective and hepatoprotective agents) and cosmetic industries (perfumes and eye-make up powders) [40, 41].

\subsection{Global Market of Value Added Compounds Obtained from Microalgae}

The PUFA fatty acids (DHA \& EPA) have a global market value of over 700 Million US\$/annum followed by $\beta$-carotene with 261 Million US\$/annum, then comes astaxanthin with a market value of 240 Million US\$/annum, closely followed by lutein with a market value of 233 Million US\$/annum and finally phycobiliproteins with a value of just over 60 Million US\$/annum [38]. The global demand for carotenoids is still expected to increase further to 1.8 billion US\$ by the end of 2019 [42].

\section{Microalgal Biomass as Human Feed}

Microalgae are rich sources of carbohydrates, proteins, and lipids. They have been used as a source of food for humans in China and Japan and in Africa and Mexico due to their abundant composition in proteins (up to $70 \%$ of dry weight), vitamins and essential fatty acids. Until today, Chlorella and Spirulina have been the most commonly sold food-microalgae because they can grow faster. Nonetheless, the biomass obtained from Spirulina has mainly been used for the extraction of phycocyanin [43, 44].
A study showed that phycocyanin extracted from Spirulina platensis inhibited the growth of human leukemia K562 cells [45]. Chlorella and Spirulina have been widely used in the production of tablets, capsules, and liquids and marketed as a source of vitamins and antioxidants. $\beta$-1,3-glucan contained in the biomass of Chlorella is considered to be one of the major components. This compound is known for stimulating the immune system as well as for lowering the lipid content in the bloodstream. Spirulina and Chlorella also found application as a food colorant (phycocyanin) and in the production of beverages (microalgal health drink, microalgal sour milk and microalgal green tea) [46]. In addition, Chlorella's content in carotenoids like astaxanthin, lutein and sulfated polysaccharide $\beta-1,3$ glucan, all possesses an anticancer effect and is effective in preventing atherosclerosis and hypercholesterolemia [43, 47]. D. salina, being rich in $\beta$-carotene, has been used as an orange dye in the food industry and as a vitamin $C$ supplement [5]. In addition to $\beta$ -carotene, Dunaliella also produces $\alpha$-carotene, lutein and lycopene. $\beta$-carotene obtained from Dunaliella has been known to inhibit cancer cells [48]. Dunaliella has been known to impart numerous health benefits in humans (pro vitamin A, anti-inflammatory and anticancer), however, only little data on the risks emphasizing the safety of consuming this alga has been reported. A multigenerational study on rats raised for four generations consuming 10\% Dunaliella showed no significant differences when tested for their gross pathology. However, histopathological studies revealed that there was a decrease in chronic inflammations between rats fed with algae and control animals with no adverse effects and this indicates that this alga is considered safe for human consumption [49]. Similar to other microalgae, Scenedesmus exhibited no negative effects and the toxicity assessments conducted using test animals revealed the safety of the alga for human consumption. Nutritional studies conducted on humans concluded that consumption of algae to a certain extent $(20 \mathrm{~g} / \mathrm{d})$ had no adverse effects even if the intake was prolonged for longer periods of time. Another study indicated that feeding Scenedesmus obliquus ( $S$. obliquus) to children and adults had no significant hematological effect but an increase in body weight was observed. The same study was carried out for slightly and seriously malnourished infants and the results obtained revealed that there was an increase in body weight for infants fed with an algal diet $(27 \mathrm{~g} / \mathrm{d})$ in comparison with infants who had a normal diet, with no adverse effects. It was therefore concluded that algal diet had a significant contribution for improvement of health in humans [50]. Scenedesmus species could be used as a source of antioxidants (astaxanthin) and as a rich vitamin source $\left(\mathrm{C}, \mathrm{B}_{1}\right.$, and $\left.\mathrm{B}_{2}\right)$ [51]. Arthrospira, another group of microalgal species, has been consumed by humans to reduce hyperlipemia, arterial pressure and to trigger the growth of intestinal Lactobacillus [44]. Haematococcus pluvalis has been known for its rich source of the carotenoid, astaxanthin known to act as an antioxidant or oxygen quencher as well as a powerful radical scavenger [52]. Nannochloropsis species especially Nannochloropsis oculata is considered to be rich in EPA and when administered in rats in the form of an oral suspension, it exhibited no toxic effects [53]. A study conducted on Nannochloropsis oculata showed that its freeze dried biomass 
could be used to enrich cookies and pasta with omega-3 fatty acids like EPA and DHA and this promises to offer a niche opportunity for the food industry [54]. A study on Aphanizomenon flos-aquae revealed that the alga contains omega- 3 alpha-linolenic acid which promotes good overall health [55]. A study indicated that oral administration of Aphanizomenon flos-aquae $(1.5 \mathrm{~g} / \mathrm{d})$ in humans increased the CD3+, CD4+ and CD8+ T cell subsets and CD19+ B cells. This resulted in the increase of immune surveillance. The increase in global production of microalgal species such as Arthrospira (3,000 t dry weight/y), Chlorella $(2,000$ $\mathrm{t}$ dry weight/y), D. salina (1,200 t dry weight/y) and Aphanizomenon flos-aquae (500 t dry weight/y) indicates that microalgae have a possibility of becoming an interesting source of food for human population in the years to come [56]. The production is expected to increase further by 27,552 tons by 2024 with a compound annual growth rate of $5.32 \%$ [57]. The other species that have been incorporated as food for humans include Odontella auriata, Tetraselmis chuii, Spirogryra and Oedigonium species. One of the major concern of incorporating algae as human feed is the fact that they contain large quantities of nucleic acid which undergoes metabolic degradation to uric acid and this might result in gout or kidney stones [58].

\section{Microalgal Biomass as Fish, Animal and Poultry Feed}

The use of microalgal species as feed supplements has grown rapidly in the past few decades. The biomass obtained from microalgae has been used as a feedstock for animals ranging from fish to farm animals. About $30 \%$ of the algae biomass produced worldwide is being sold as animal feed [56]. As a rich source of protein microalgae have been as a nutritional supplement for the larvae of crustaceans and molluscs for a particular period of their life cycle [59, 60]. The commonly used species of microalgae for animal feed include Chlorella, Isochrysis, Phaeodactylum, Chaetoceros, Nannochloropsis, Tetraselmis, Dunaliella, Scenedesmus, Thalassiosira and Skeletonema. The carotenoid astaxanthin, obtained from Haematococcus algae, has been endorsed in Canada as a coloring agent in salmonid feed [56]. A study reported that Haematococcus has the ability to produce larger amounts of astaxanthin when compared to other algae and has been widely used in aquaculture. The meal produced from Haematococcus has been successfully employed as fish feed for its astaxanthin content and has proven to be non-toxic on consumption [61]. Chlorella, being rich in protein content could be used as an alternative source as it is less expensive and grows rapidly [62]. Lutein obtained from Scenedesmus species is mostly used as a source for animal nutrition while astaxanthin is mostly used in the field of aquaculture. In addition, Scenedesmus species can be considered as a source of monounsaturated, polyunsaturated and saturated fatty acids in animal and fish feeds [51]. Spirulina sp., contains nutrients such as proteins, carbohydrates, and vitamins and has the ability to grow in highly saline and alkaline medium. Hence, these species provide a valuable feed for livestock. A study on the impact of Spirulina on growth and pigmentation in broiler chickens showed that there was no change in body weight, however there were increments in yellowness and redness of the broiler flesh. The yellowness was possibly due to the accumulation of zeaxanthin (yellow pigment) within the flesh $[63,64]$. The powder form of $\beta$-carotene obtained from Dunaliella species was used as a coloring agent and as a source of pro-vitamin A for animals and fish [65]. Nannochloropsis species being rich in EPA have been used as a nutritional supplement in the aquaculture industry [63]. The effect of inclusion of Nannochloropsis gaditana in the diet of hens revealed that there was an increase in the content of DHA present in their produced egg yolk and it could be used as an alternative to produce eggs enriched with DHA [66]. A study reported that up to $16 \%$ of the dried Spirulina algae, when introduced into broiler diet, had a significant impact on the performance of the chicks [67]. A study revealed that Spirulina platensis, when incorporated into mash starter and finisher diet, increased the chicks' performance in terms of Body Weight Gain and Feed Conversion Ratio [68]. Another study revealed that the incorporation of $2.0 \%$ and $2.5 \%$ Spirulina platensis biomass in the poultry feed has the potential to improve the colour of the egg yolk without any significant effect on production performance [69]. An investigation to study the impact of dietary supplementation of Chlorella vulgaris in poultry feed showed that the inclusion of $1 \%$ of fresh liquid Chlorella in the diet of chicks improved their growth performance. There was also an increase in their intestinal microflora and improvement in the functioning of their immune system [70]. Fermented Chlorella vulgaris biomass incorporated into poultry feed was studied for its effects on egg production, egg quality, liver lipids and intestinal microflora in laying hens. The results revealed that there was an improvement in egg production, egg yolk colour and positive effect on the contents of hepatic triglycerol and the profiles of cecal microflora [71]. Kotrbacek, Skrivan et al. (2013) studied the effect of incorporation of $1 \%$ and $2 \%$ of Chlorella biomass into the dietary supplementation of poultry feed and revealed that there was an increase in yolk carotenoids, lutein, $\beta$-carotene and zeaxanthin with both $1 \%$ and $2 \%$ inclusions [72]. The inclusion of four species of microalgae Phaeodactylum tricornutum, Nannochloropsis oculata, Isochrysis galbana and Chlorella fusca in the poultry feed concluded that inclusion of $125 \mathrm{mg} / 100 \mathrm{~g}$ of feed of Phaeodactylum tricornutum and Isochrysis galbana increased the long chain PUFA content as well as the colour of the egg yolk. Therefore, these two species could be used as an alternative to current sources for enrichment of eggs [73]. Microalgal biomass, if incorporated into the feed of animals, can positively influence the growth, immune response and gut function [74]. Therefore, from the above discussion it is evident that microalgal biomass can be used as animal, fish, or poultry feed.

\section{Microalgal Biomass in the Field of Cosmetics}

The current trend in the world of cosmetics is developing products that meet consumers demand for products which provide multiple benefits with little or no efforts. Cosmetic pharmaceuticals, known in short as cosmeceuticals, contain bio actives that are mainly used to improve the biological skin function, thereby 
imparting a therapeutic effect [75]. Recently, microalgae are receiving great attention because of the fact that they can be effectively used in the treatment of skin disorders like aging, tanning, and problems related with pigmentation [76]. The commonly used algae employed in cosmetic industries include Spirulina sp., Chlorella sp., and Arthrospira sp. [77]. Conventional methods such as maceration, aqueous extraction, and soxhlet extraction are still the widely used techniques for extracting bioactive compounds from algae [78]. Microalgae have been used as skin whitening agents by inhibiting the tyrosinase enzyme which in turn leads to the reduction of melanin pigment. This is considered to be the most common approach for skin whitening as melanin is the compound that is responsible for the colour of the skin, hair and eyes [79]. Fucoxanthin and phloroglucinol derivates acquired from marine microalgae have the ability to inhibit the formation of melanin. Hence, marine microalgae have been considered to be a promising tool as tyrosinase inhibitor agents.

Skin wrinkling occurs due to the formation of matrix metalloproteinase that leads to the degradation of skin collagen and this is generally caused by reactive oxygen species due to oxidative stress. The phenolic compounds obtained from marine microalgae have shown to inhibit the formation of matrix metalloproteinase, thereby preventing skin aging [80]. Polysaccharides obtained from microalgae have a large number of cosmetic functions. Fucoidans acquired from brown algae, carrageenans obtained from red algae and ulvans obtained from green algae are some of the best examples. They are used as rheology modifiers, hair conditioners, suspending agents and wound-healing agents [81]. The extracts obtained from biomass of Chlorella and Spirulina have been used in the production of creams, lotions, shampoos and sun protection commodities. The Pentapharm Company of Switzerland has found that Nannochloropsis oculata could be used for skin elasticity while the Exsymol company of Monaco has used the extract of Arthrospira for slowing down skin aging [44].

The processing of algae in the cosmetic industry starts with the collection of microalgal strain followed by cultivation. The culture conditions have been optimized and the algal biomass has successfully been separated by means of filtration, sedimentation or flocculation. Once produced the biomass is then dewatered and dried. The cells obtained from the culture are further disrupted using milling, grinding or powdering. The last step is the extraction of the desired product from the algal biomass using micronization or extraction techniques [77]. Microalgal biomass can be a valuable source of extractable compounds of interest to the cosmetic industry because of the diversity of their biological activity. However, in order to commercialize cosmetic products from microalgae there is a need for conducting stability and toxicological studies to ensure their safety and efficacy [82].

\section{Microalgal Biomass in the Field of Pharmaceuticals}

The worldwide market for pharmaceuticals is rising day by day and algae have been considered to be a prospect in satisfying the increasing demand [81]. The primary and secondary metabo- lites produced by microalgae can be used as ingredients for the pharmaceutical industry [83]. An increase in the production of bioactive compounds from natural sources (microalgae) has been observed and is considered to be an emerging area of particular interest in the years to come [84]. The most commonly employed microalgae for the production of bioactive compounds, of pharmaceutical interest, include Arthrospira (Spirulina), Chlorella, Dunaliella, Haematococcus and Nostoc. The production of vaccines from microalgae that can be administered orally seems to be an interesting aspect for researchers to concentrate on in the future. As per advances in microalgal research, Chlamydomonas reinhardtii was found to be one of the most important microalgae that have been employed in the manufacturing of pharmaceutical proteins (erythropoietin, interferon $\beta$ insulin and immunoglobin A) [85, 86]. Glycerol, a compound widely used in pharmaceutical industries was produced by Chlamydomonas reinhardtii when the alga was deprived of sulfur [87]. Cyanovirin, a bioactive compound obtained from the biomass of Nostoc responded positively for treating symptoms of HIV and influenza A (H1N1). Besides this, Nostoc also produces essential fatty acids and polyunsaturated fatty acids. The biomass of Chlorella species is known to be rich in Vitamin $\mathrm{B}$ complex especially $\mathrm{B}_{12}$, $\alpha$-carotene, $\beta$-carotene, lutein, ascorbic acid and $\alpha$-tocopherol and these compounds can help in decreasing the occurrence of certain cancer and in preventing macular degeneration. Dunaliella was also considered to be a rich source of bioactive compounds such as enzymes and vitamins. The crude extract obtained from this alga strongly limited the growth of harmful bacteria, thereby acting as an effective antimicrobial [88]. Table 1 presents many of the value added compounds produced by microalgal species for pharmaceutical purposes [89].

Table 1. Microalgal Species Producing High-value Compounds for Pharmaceutical Purposes (adapted from [89])

\begin{tabular}{|c|c|c|}
\hline S.No & Name of the microalgae & Product obtained \\
\hline 1 & Chlorella sp. & $\begin{array}{l}\text { Lutein, } \beta \text {-carotene, } \alpha \text {-carotene, } \\
\alpha \text {-tocopherol }\end{array}$ \\
\hline 2 & Crypthecodinium cohnii & Docosahexaneoic acid \\
\hline 3 & Haematococcus pluvalis & $\begin{array}{l}\text { Carotenoids, astaxanthin, } \\
\text { lutein }\end{array}$ \\
\hline 4 & Nannochloropsis gaditana & Eicosapentaneoic acid \\
\hline 5 & Scenedesmus almeriensis & Lutein, $\beta$-carotene \\
\hline 6 & Chlamydomonas reinhardtii & Glycerol \\
\hline
\end{tabular}

\section{Microalgal Biomass in the Field of Biodiesel Production}

Biodiesel can be manufactured from oils or lipids obtained from a variety of sources. Triglycerols are considered to be the main component essential for the production of biodiesel. The commonly used sources of fats for the production of biodiesel include pure vegetable oil, animal fats and waste cooking oils. However recently, microalgae have been considered to be a potential source 
for biodiesel production due to the limited supply of other sources, especially from food-based sources. Microalgae have the ability to multiply at various rates and thrive in a variety of temperatures and environments [90] and the oil content they produce can be very high (up to $80 \%$ of dry weight) when compared to other traditional feedstocks. Therefore, microalgae are considered to be a key pathway for biodiesel production [91]. There are different methods available for converting microalgal biomass into biofuels. These include biochemical conversion, thermochemical conversion, chemical reaction and direct combustion. Transesterification is a chemical reaction process that is commonly employed for converting lipids into biodiesel [92]. The biodiesel produced from microalgae has high caloric value and the viscosity and density of the fuel obtained is lower when compared to biodiesel obtained from other feedstocks. Microalgae biodiesel does not contain sulfur or aromatics and this helps in the substantial reduction of carbon monoxide and particulate matter emissions on ignition [93]. In addition, only $0.3 \%$ of the transport fuels are obtained from oil crops and animal fats. The food supply could be affected globally if more arable lands were used for increasing biofuel production. Hence, microalgae are considered to be the only option for producing biodiesel in a sustainable way as they have the ability to grow even on wastewaters and adapt themselves to changing environmental conditions [90]. A study carried out using Chlorella sorokiniana strain under a variety of culture conditions revealed a buildup of target fatty acids that could be used as a feedstock for producing a biodiesel of good quality [94]. An investigative study with Scenedesmus sp., for increasing productivity of biodiesel, has shown that in situ transesterification process at $70^{\circ} \mathrm{C}$, reaction time of $10 \mathrm{~h}$ and biomass to solvent ratio of $1: 15$ using a $5 \%$ acid catalyst (sulfuric acid) generated pure biodiesel when compared to using a $5 \%$ alkaline catalyst (sodium hydroxide) [95]. A study conducted using $S$. obliquus cultivated in simulated brewery effluent showed that production of biodiesel from the oil extracted from $S$. obliquus is possible as it contains almost equal proportions of saturated (56.4\%) and unsaturated esters (43.6\%; Linoleate - 11.42\%) [96], and this is desirable since saturated esters contribute to the higher stability of the biodiesel whereas unsaturated esters contribute to the lower pour points. Cetane number, density and viscosity also depend on the ratio of saturated to unsaturated esters. The higher the degree of saturation, the higher is the cetane number (time taken for the fuel to ignite), viscosity and density [97]. The lipase enzyme extracted from Scenedesmus dimorphus could serve as a potential catalyst for transesterification with the help of methanol, ethanol or proponal for producing biodiesel. A yield of $44 \%$ of fatty acid methyl esters was obtained after $24 \mathrm{~h}$ of reaction with methanol when compared to other two solvents (24\% and 22\%) [98]. A previous study on Scenedesmus bijuga cultivated in food wastewater effluent showed that the alga had a dual potential of treating wastewater as well as for producing biodiesel [99]. In another study, Scenedesmus sp., isolated from the coast of Odisha in India, had a high lipid productivity of $24.66 \mathrm{mg} / \mathrm{L}^{*} \mathrm{~d}$ hence, could be used as a potential candidate for biodiesel production [100]. A study showed that Scenedesmus acuminatus cultivated on piggery effluent could be used as a potential candidate for bio- diesel production. The study also revealed that it is possible to produce biodiesel directly using transesterification from wet microalgal biomass in a single step without the need of drying, thereby making it economically feasible [101]. A study conducted on the biomass of Dunaliella and Nannochloropsis sp., showed that direct transesterification of the respective microalgal biomass yielded $66.6 \%$ and $68.5 \%$ (dry basis) of biodiesel respectively. The amount of palmitic acid, oleic acid and linolenic acid that are considered to be major components for producing biodiesel was found to be high and hence served as a promising feedstock for biodiesel production [102]. An investigation revealed that $D$. salina was capable of producing biodiesel as the amount of saturated fatty acids to unsaturated fatty acids was in the proportion of 1:2 (35\%:65\% dry basis) thereby increasing the cetane number of the produced biodiesel [103]. Another study on the biodiesel obtained from $D$. salina revealed that moderate quantity of linolenic and linoleic acid was present during Fatty Acid Methyl Esters (FAME) analysis. The presence of both linolenic and linoleic acid could produce biodiesel with higher oxidative stability due to more methylene carbons allylic sites however; very high oxidative stability will decrease its acid value and viscosity. This also influences the quality of the fuel obtained. Therefore, $D$. salina is considered to be a suitable feedstock for biodiesel production due to the presence of high amount of lipids and saturated fatty acids [104]. A study on three marine microalgal species Isochrysis galbana, Pavlova lutheri and D. salina showed that Pavlova lutheri produced more biodiesel than Isochrysis galbana and D. salina. The density and the viscosity of the oil were also measured. The study concluded that density of oil (an important fuel quality parameter) obtained from microalgae was high and agreed with ASTM D941 test standard method when compared to density obtained from other sources [105]. A study concluded that D. salina is a potential candidate for biodiesel production since it has the capability to grow in conditions which are not sterile and the amount of lipid produced by this micro-alga is high at $45 \mathrm{mg}$ lipid/L*day. Besides this, D. salina can also produce $\beta$-carotene as a value-added byproduct and this builds up the feasibility of using $D$. salina for biodiesel production as it reduces the overall cost [106]. A study conducted on 9 Nannochloropsis sp., namely Nannochloropsis gaditana, Nannochloropsis salina, Nannochloropsis granulata, Nannochloropsis limnetica, Nannochloropsis ocenaica $(N$. ocenaica) and Nannochloropsis oculata for biodiesel production showed that the excellent strain for biodiesel production was $N$. ocenaica because of its higher lipid productivity of 158.76 $\pm 13.83 \mathrm{mg} / \mathrm{L}^{*} \mathrm{~d}$, cetane number of $54.61 \pm 0.25$ and lower iodine number of $104.85 \pm 2.80 \mathrm{gI}_{2} / 100 \mathrm{~g}$ as well as low cloud point of $3.45 \pm 0.5^{\circ} \mathrm{C}$ [107]. The properties of biodiesel obtained from microalgae seem to be similar to those obtained from oil seed crops and fossil fuels. However, biodiesel from microalgae is considered to be an environmentally friendly and sustainable fuel for the future [108]. Unfortunately, the cost associated with producing biodiesel from microalgae is relatively high. Genetic engineering is an avenue to be explored as it has the scope of increasing the microalgal biomass productivity by producing superior strains and consequently increasing the biodiesel production [109]. In a nutshell, if biodiesel from microalgae is com- 
mercialized then it would serve as a solution for replacing conventional transport fuels as studies have shown that microalgae have the potential to produce more biodiesel when compared to other oil producing crops [5]. The usage of a biorefinery concept would be an added advantage as the residual biomass obtained after biodiesel extraction could be used as a source of protein for animal feed or in the production of specialty ingredients. This tends to improve the efficiency of the process as well as reduces the cost involved making it technically sustainable [110, 111].

\section{Microalgal Biomass in the Field of Biohydrogen Production}

A lot of research has been conducted in the early 70's for manufacturing hydrogen from microalgae using sunlight and water. The microalgae commonly employed in the production of hydrogen include Chlamydomonas reinhardtii, Chlorella fusca, Chlorella sorokiniana, S. obliquus, Chlorococcum littorale and Platymonas subcordiformis [112]. S. obliquus, a green alga was the first microalgae reported to produce low quantity of hydrogen in the dark. The production of hydrogen was enhanced when the microalga was exposed to light [113]. The various processes involving biohydrogen production from microalgae include direct biophotolysis, indirect biophotolysis, dark fermentation and photo-fermentation [114, 115]. Chlamydomonas reinhardtii has the ability to produce hydrogen and this is dependent on the expression of hydrogenase enzyme. The expression of this enzyme is found to be 10 to 100 fold when compared to other species of microalgae. However, biohydrogen production from Chlamydomonas reinhardtii has not yet reached commercial production due to engineering problems related to scale [116]. A study on the strain of Chlorella sorokiniana revealed that the micro-alga could produce a high amount of biohydrogen when the amount of sulfur was limited. The biohydrogen produced was then used to power a Proton Exchange Membrane (PEM) fuel cell which showed good performance under ideal conditions [117]. In another study by Ali et al. (2011), three strains of Chlorella sp., (Chlorella vulgaris TISTR 8680, Chlorella ellipsoidea TISTR 8260 and Chlorella sp. TISTR 8262) were studied to determine their capability for producing biohydrogen [118]. The strains under study were cultured under an anaerobic setup in BG-11 and sulfur-deprived BG-11 medium. The results exhibited that Chlorella sp., TISTR 8262 had the highest biohydrogen production of $13.03 \%$, followed by Chlorella ellipsoidea TISTR 8260 which had a yield of 3.05\%. Chlorella vulgaris TISTR 8680 on the other hand, did not produce any hydrogen [118]. A study on marine alga Platymonas subcordiformis demonstrated that the alga was able to produce biohydrogen when deprived of sulfur [119]. Therefore, for biohydrogen production from microalgae to be commercially successful, strains should be genetically modified or strains which are able to survive under sulfur-deprived conditions should be used. The biggest challenge that researchers face today is the inclusion of such traits in a single strain [120].

\section{Microalgal Biomass in the Field of Bioethanol Production}

Bioethanol is obtained from various biomass feedstocks through different conversion technologies. The bioethanol obtained from sugar/starch crops through traditional production technologies are generally classified under "First generation biofuels", whereas the bioethanol obtained from lignocellulosic biomass is classified under "Second generation biofuels" [121]. However, bioethanol obtained from sugar/starch crops occupies more land and cultivation of such crops for this very purpose creates competition with global food supply [122]. In this perspective, microalgae are gaining wide attention as a feedstock for bioethanol production [123]. The most commonly used microalgae for bioethanol production include Chlorella sp., Chlamydomonas reinhardtii, Chlorococcum sp., Scenedesmus sp., and Spirulina fusiformis. A study on Chlorella vulgaris revealed that they could serve as a potential feedstock for production of bioethanol as they have shown the ability to accumulate a high amount of starch (37\%) [124]. Another study on unicellular marine green alga Chlorococcum littorale on starch substrate revealed that dark fermentation led to the decomposition of cellular starch that was accumulated in the cells of the micro-alga. The decomposition of cellular starch in turn led to the formation of ethanol, carbon dioxide and hydrogen as fermentation products. The study also revealed that maximum productivity of ethanol was observed at $30^{\circ} \mathrm{C}(450 \mu \mathrm{mol} / \mathrm{g}$-dry wt.) [125]. A screen of 200 strains of microalgae from seawater revealed that one particular strain Chlamydomonas sp. YA-SH-1 had the ability to convert almost $50 \%$ of its $30 \%$ starch content (dry basis) into ethanol under dark and anaerobic conditions [126]. S. obliquus CNW-N was able to produce high amount of carbohydrates (42\%) under controlled laboratory conditions. This along with acid hydrolysis with $2 \%$ sulfuric acid, gave a bioethanol yield of $8.55 \mathrm{~g} / \mathrm{L}$ [127]. A previous study on Chlorococcum humicola revealed that the pre-treatment of the alga, with $1 \% \mathrm{v} / \mathrm{v}$ of sulfuric acid for 30 $\min$ at $140^{\circ} \mathrm{C}$, increased the bioethanol production from $16 \%$ to $52 \%$ [128]. A study revealed that Spirulina platensis had the ability to produce $16.32 \%$ and $16.27 \%$ of bioethanol production at $100^{\circ} \mathrm{C}$ when treated with $0.5 \mathrm{~N}$ nitric acid and $0.5 \mathrm{~N}$ sulfuric acid respectively [129]. The production of bioethanol from microalgae can therefore be obtained through any one of the following methods: from algal metabolites, dark fermentation and direct production by engineered microalgae. Hence, bioethanol obtained from biomass of microalgae is considered to be a suitable alternative when compared to other traditional technologies however commercialization is yet to begin [130].

\section{Microalgal Biomass as Biofertilizers}

Fertilizers contain nutrients that are essential for plant growth. Fertilizers play a vital role in improving agriculture thereby increasing production. Arable land is being used continuously for the cultivation of crops and these results in the loss of nutrients 
that are essential for the optimal growth of plants. The most common nutrients incorporated into fertilizers include nitrogen and phosphorus. The cost of production of chemical fertilizers is rising; hence a suitable alternative is required. The use of biofertilizers produced from microalgae would provide a possible solution [131]. Biofertilizers are products that are cheap and contain natural compounds derived from micro-organisms such as algae, bacteria and fungi that can help in improving soil fertility and stimulating plant growth [132]. The majority of cyanobacteria is capable of fixing atmospheric nitrogen and can be effectively used as biofertilizers. They can help build-up soil fertility thereby enhancing crop yield as demonstrated with rice [133]. A study showed that the dry biomass obtained from Acutodesmus dimorphus applied as a biofertilizer was able to increase the growth of plant and production of flowers in Roma tomato plants [134]. The growth parameters in lettuce plant were studied using Chlorella vulgaris as biofertilizer. A study revealed that the dry powder of Chlorella vulgaris was considered to be a suitable substrate for germinating the seeds of Lactuca sativa as it significantly enhanced the process of germination when compared to unfertilized control. It also increased significantly the amount of pigments (chlorophyll a, chlorophyll b and carotenoids) in the lettuce seedlings. Therefore, the study concluded that dry microalgae could be used as plant nutrients for ideal growth as it can improve soil fertility [135]. A treatment study containing two formulations i.e., formulation with unicellular microalgae (MC1) and formulation with filamentous microalgae (MC2), applied as a biofertilizer for wheat crop, revealed that the formulation with filamentous microalgae (MC2) increased the nitrogen, phosphorus and potassium in the soil with an improvement in the yield when compared to the formulation with unicellular algae (MC1). This study, therefore, supports the use of microalgal consortia as a biofertilizer for increasing crop yield [136]. The impact of two microalgae Chlorella vulgaris and Spirulina platensis on maize crop was studied with various treatments. The results concluded that microalgal treatment with cow dung manure + Spirulina platensis and cow dung manure + Chlorella vulgaris enhanced the yield and growth of maize up to $51.1 \%$ following $60 \mathrm{~d}$ after planting [137].

\section{The Concept of Biorefinery}

Biorefining is a process by which biomass is converted into value added products and energy in a sustainable way. Countries that currently apply this concept include US, England, Canada, China, Japan and Spain [138]. The success of a biorefinery depends largely on the raw material selected and the technologies/processes involved in obtaining the value added products. Microalgae are considered to be one such raw material that can be exploited for this purpose in an economical way. Microalgae unlike terrestrial plants lack highly resistant cell wall components with no stem or roots which makes the degradation easier for exploitation of value added products. The method that can be employed for technical realization of this concept is to produce high value added products with residual biomass valorization in the form of a fuel. The initial step involved is extraction of the desired value added product from the cell and this largely depends on the strain under study and the cultivation conditions. The final step is fractionating the residual biomass into different by-products or energy. A biorefinery setup should therefore, take into consideration the following aspects such as biomass productivity, strain used along with their biochemical composition and the possibility of extracting value added products [110]. A general schema of a microalgal biorefinery is presented in Fig. 1.

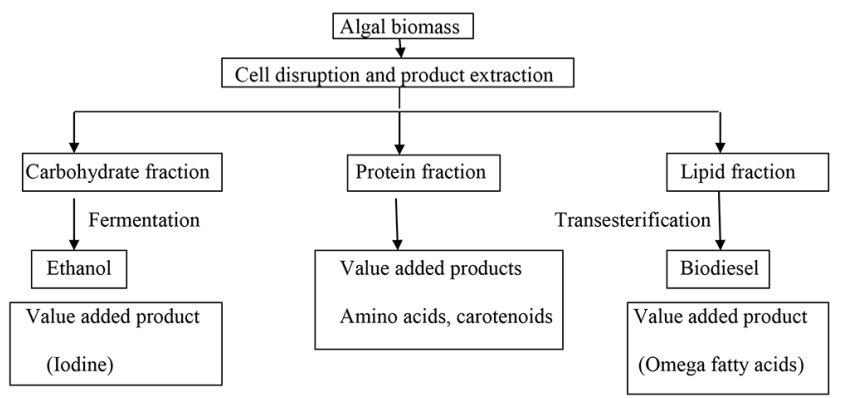

Fig. 1. General Schema of a microalgal biorefinery (adapted from [111]).

\section{Conclusions}

The microalgal industry is still in its infancy of industrial development, yet is seen as a gateway for a multibillion industry in the years to come as it microalgae are considered to be an ecologically safe feedstock for biofuels and for producing products that fetch high commercial value. Microalgae are considered to produce more oil for biodiesel development than any other terrestrial plants (soya, rapeseed, palmoil and jatropha). Besides this, they are also known to produce certain highly valued carotenoids like $\beta$-carotene and astaxanthin which have been commercialized. They also possess the power of converting any type of wastewater into a low environmental impact effluent which in turn could serve as a biofertilizer for plants by improving the fertility of the soil. The need for this sector to be further developed is rising as there has been a constant demand for innovations that are eco-friendly in order to meet the needs of humans with respect to food, water or fuel (the three most essential things). Based on the literature reviewed, a lot of emphasis has been given for obtaining biodiesel from microalgae over the past few decades, thereby, limiting the exploration of using microalgae in other applications such as pharmaceutical, nutritional and cosmetic industries. For efficient extraction of valuable products from microalgae, large amount of biomass is required and future research should take this aspect into consideration. The usage of an integrated biorefinery concept should be given importance as this will make exploitation of microalgae cheaper and competitive when compared with other sources. Algal consortium could be used for treating wastewater effectively and promptly. Another avenue for advancement of this technology is to induce certain genes of interest in algae for producing products that are of interest and have high commercial value. Bioprospecting and selection of algal strains combined 
with genetic engineering holds the key for making this technology successful. In conclusion, the application of microalgae in pharmaceutical, agricultural and cosmetic industries is still in its infancy and further developments will be required to make this field of production, one of the future.

\section{Acknowledgments}

The authors would like to acknowledge NSERC (Natural Sciences and Engineering Research Council of Canada) for their financial support.

\section{References}

1. Shivhare S, Mishra AK, Sethi VK, Bhadoria AKS. Growth rate, biochemical and biomass analysis of scenedesmus obliquus algae in Shahpura Lake Bhopal (MP). Int. J. Pharm. Chem. Sci. 2014;3:477-482.

2. Mutanda T, Ramesh D, Karthikeyan S, Kumari S, Anandraj A, Bux F. Bioprospecting for hyper-lipid producing microalgal strains for sustainable biofuel production. Bioresour. Technol. 2011;102:57-70.

3. Sumi Y. Microalgae pioneering the future-application and utilization. Sci. Technol. Trend. 2009;34:9-21.

4. Mata TM, Martins AA, Caetano NS. Microalgae for biodiesel production and other applications: A review. Renew. Sust. Energ. Rev. 2010;14:217-232.

5. Priyadarshani I, Rath B. Commercial and industrial applications of micro algae - A review. J. Algal Biomass Utln. 2012;3:89-100.

6. Hannon M, Gimpel J, Tran M, Rasala B, Mayfield S. Biofuels from algae: Challenges and potential. Biofuels 2010;1:763-784.

7. Ercin AE, Aldaya MM, Hoekstra AY. The water footprint of soy milk and soy burger and equivalent animal products. Ecol. Indic. 2012;18:392-402.

8. Rashida N, Rehmanb MSU, Sadiqd M, Mahmoode T, Han JI. Current status, issues and developments in microalgae derived biodiesel production. Renew. Sust. Energ. Rev. 2014;40:760-778.

9. Schenk P M, Thomas-Hall SR, Stephens E, et al. Second generation biofuels: High-efficiency microalgae for biodiesel production. Bioenergy Res. 2008;1:20-43.

10. Rajesh G, Roshan M, Krishnamurthy V, Bhattacharjee S. Production of lipids in photobioreactors using microalgae. Int. J. Sci. Eng. Res. 2014;5:1223-1238.

11. Pulz O, Gross W. Valuable products from biotechnology of microalgae. Appl. Microbiol. Biotechnol. 2004;65:635-648.

12. Minhas AK, Hodgson P, Barrow CJ, Adholeya A. A review on the assessment of stress conditions for simultaneous production of microalgal lipids and carotenoids. Front Microbiol. 2016;7:1-19

13. The next big superfood could be green and slimy [Internet]. Baehr: c2011 [cited 07 August 2017]. Available from: http://www.businessinsider.com/algae-is-the-superfood-of-the-future-2014-6.
14. Misra R, Guldhe A, Singh P, Rawat I, Bux F. Electrochemical harvesting process for microalgae by using nonsacrificial carbon electrode: A sustainable approach for biodiesel production. Chem. Eng. J. 2014;255:327-333.

15. Borowitzka MA. High-value products from microalgae - Their development and commercialisation. J. Appl. Phycol. 2013;25:743-756

16. Mozaffarieh M, Sacu S, Wedrich A. The role of the carotenoids, lutein and zeaxanthin, in protecting against age-related macular degeneration: A review based on controversial evidence. Nutr. J. 2003;2:1-8.

17. Fernández-Sevilla JM, Fernández FA, Grima EM. Biotechnological production of lutein and its applications. Appl. Microbiol. Biotechnol. 2010;86:27-40.

18. Guedes AC, Amaro HM, Malcata X. Microalgae as sources of carotenoids. Mar. Drugs 2011;9:625-644.

19. Sánchez JF, Fernández-Sevilla JM, Acién FG, Cerón MC, Pérez-Parra J, Molina-Grima E. Biomass and lutein productivity of Scenedesmus almeriensis: Influence of irradiance, dilution rate and temperature. Appl. Microbiol. Biotechnol. 2008;79:719-729.

20. Molina E, Fernandez JM, Acien FG, et al. Production of lutein from the microalga Scenedesmus almeriensis in an industrial size photobioreactor: Case study. In: Oral presentation at the 10th International Conference on Applied Phycology, Kunming, China; 2005.

21. Panis G, Carreon JR. Commercial astaxanthin production derived by green alga Haematococcus pluvialis: A microalgae process model and a techno-economic assessment all through production line. Algal Res. 2016;18:175-190.

22. Shah M, Mahfuzur R, Liang Y, Cheng JJ, Daroch M. Astaxanthin-producing green microalga Haematococcus pluvialis: From single cell to high value commercial products. Front. Plant Sci. 2016;7:1-28.

23. Cuellar-Bermudez SP, Aguilar-Hernandez I, Cardenas Chavez DL, Ornelas-Soto N, Romero-Ogawa MA, ParraSaldivar R. Extraction and purification of high-value metabolites from microalgae: Essential lipids, astaxanthin and phycobiliproteins. Microb. Biotechnol. 2015;8:190-209.

24. Pisal DS, Lele SS. Carotenoid production from microalga, Dunaliella salina. Ind. J. Biotechnol. 2005;4:476-483.

25. Sajilata M, Singhal R, Kamat M. The carotenoid pigment zeaxanthin - A review. Compr. Rev. Food Sci. Food Safe. 2008;7:29-49.

26. Granado-Lorencio F, Herrero-Barbudo C, Acién-Fernández $\mathrm{G}$, et al. In vitro bioaccesibility of lutein and zeaxanthin from the microalgae Scenedesmus almeriensis. Food Chem. 2009;114:747-752.

27. Guillerme JB, Couteau C, Coiffard L. Applications for marine resources in cosmetics. Cosmetics 2017:4:1-15.

28. Market opportunities for microalgae-based biorefineries [Internet]. Jesse: c2016 [cited 01 Feb 2018]. Available from: https://insightrefinery.wordpress.com/2016/02/08/market-opportunities-for-microalgae-based-biorefineries/.

29. Winwood RJ. Recent developments in the commercial production of DHA and EPA rich oils from micro-algae. OCL 2013;20:1-5. 
30. Patil V, Reitan KI, Knutsen G, et al. Microalgae as source of polyunsaturated fatty acids for aquaculture. Plant Biol. 2005;6:57-65.

31. Patil V, Källqvist T, Olsen E, Vogt E, Gislerød HR. Fatty acid composition of 12 microalgae for possible use in aquaculture feed. Aquacult. Int. 2007;15:1-9.

32. Matos J, Cardoso C, Bandarra N. M, Afonso C. Microalgae as healthy ingredients for functional food: A review. Food Funct. 2017;8:2672-2685.

33. Agarwal S, Rao AV. Tomato lycopene and its role in human health and chronic diseases. Can. Med. Assoc. J. 2000;163: 739-744.

34. Mourelle ML, Gómez CP, Legido JL. The potential use of marine microalgae and cyanobacteria in cosmetics and thalassotherapy. Cosmetics 2017;4:1-14.

35. Giovannucci E. Tomatoes, tomato-based products, lycopene, and cancer: Review of the epidemiologic literature. J. Nat. Can. Inst. 1999;91:317-331.

36. Schweiggert RM, Carle R. Carotenoid production by bacteria, microalgae, and fungi. In: Kaczor A, Baranska M, eds. Carotenoids: Nutrition, analysis and technology. John Wiley \& Sons, Ltd.; 2016. p. 217-240.

37. Renju G, Kurup GM, Kumari CS. Effect of lycopene from Chlorella marina on high cholesterol-induced oxidative damage and inflammation in rats. Inflammopharmacology 2014;22:45-54.

38. Markou G, Nerantzis E. Microalgae for high-value compounds and biofuels production: A review with focus on cultivation under stress conditions. Biotechnol. Adv. 2013;31: 1532-1542.

39. Sekar S, Chandramohan M. Phycobiliproteins as a commodity: trends in applied research, patents and commercialization. J. Appl. Phycol. 2008;20:113-136.

40. Odjadjare EC, Mutanda T, Olaniran O. Potential biotechnological application of microalgae: A critical review. Crit. Rev. Biotechnol. 2017;37:37-52.

41. De Jesus Raposo MF, de Morais RMSC, de Morais AMMB. Health applications of bioactive compounds from marine microalgae. Life Sci. 2013;93:479-486.

42. Carotenoids - Global Market Outlook [Internet] Anonymous: 2017 [cited 17 December 2017]. Available from: https://www.reportlinker.com/p04670904/Carotenoids-Glob al-Market-Outlook.html.

43. Soletto D, Binaghi L, Lodi A, Carvalho JCM, Converti A. Batch and fed-batch cultivations of Spirulina platensis using ammonium sulphate and urea as nitrogen sources. Aquaculture 2005;243:217-224.

44. Varfolomeev SD, Wasserman LA. Microalgae as source of biofuel, food, fodder, and medicines. Appl. Biochem. Microbiol. 2011;47:789-807.

45. Liu Y, Xu L, Cheng N, Lin L, Zhang C. Inhibitory effect of phycocyanin from Spirulina platensis on the growth of human leukemia K562 cells. J. Appl. Phycol. 2000;12:125-130.

46. Liang S, Liu X, Chen F, Chen Z. Current microalgal health food R \& D activities in China. Hydrobiologia 2004;512:45-48

47. Talero Barrientos EM, García-Mauriño S, Román A, et al. Bioactive compounds isolated from microalgae in chronic inflammation and cancer. Mar. Drugs 2015;13:6152-6209.
48. Bishop MA, West, Zubeck M. Evaluation of microalgae for use as nutraceuticals and nutritional supplements. Nutr. Food Sci. 2012;2:1-6.

49. Mokady S, Abramovici A, Cogan U. The safety evaluation of Dunaliella bardawil as a potential food supplement. Food Chem. Toxicol. 2014;27:221-226.

50. Gross U, Gross R. Acceptance and product selection of food fortified with the microalga Scenedesmus. In: Carl JS, Binsack R, eds. Microalgae for food and feed. Stuttgart: Archiv fur Hydrobiologie Beihefte Ergebnisse der Limnologie;1978. p. 174-183.

51. Ishaq AG, Matias-Peralta HM, Basri H. Bioactive compounds from green microalga-scenedesmus and its potential applications: A brief review. Pert. J. Trop. Agr. Sci. 2016;39:1-16.

52. Sousa I, Gouveia L, Batista P, Raymundo A, Bandarra N. Microalgae in novel food products. In: Konstantinos N, Papadopoulos, eds. Food chemistry research developments. Nova Science Publishers; 2008. p. 75-112.

53. Kagan ML, Matulka RA. Safety assessment of the microalgae Nannochloropsis oculata. Toxicol. Rep. 2015;2:617-623.

54. Babuskin S, Krishnan KR, Babu PAS, Sivarajan M, Sukumar M. Functional foods enriched with marine microalga Nannochloropsis oculata as a source of [omega]-3 fatty acids. Food Technol. Biotechol. 2014;52:292-299.

55. Jensen GS, Ginsberg DI, Drapeau C. Blue-green algae as an immuno-enhancer and biomodulator. J. Nutraceu. Nutri. 2001;3:24-30.

56. Spolaore P, Joannis-Cassan C, Duran E, Isambert A. Commercial applications of microalgae. J. Biosci. Bioeng. 2006;10:87-96.

57. Algae market, by application, by cultivation technology, and geography - Global industry analysis, size, share, growth, trends, and forecast - 2016-2024 [Internet]. Anonymous: 2016 [Cited 17 December 2017]. Available from: https://www. prnewswire.com/news-releases/global-algae-market-is-projected-to-be-worth-us11-bn-by-2024-at-a-cagr-of739-global-industry-analysis-size-share-growth-trends-andforecast-2016---2024-tmr-594253011.html.

58. García JL, Vicente M, Galan B. Microalgae, old sustainable food and fashion nutraceuticals. Microb. Biotechnol. 2017;10:1017-1024.

59. Borowitzka MA. Algae as food. In: Wood BJB, ed. Microbiology of fermented foods. 2nd ed. Boston, MA: Thomson Science Boston, MA: Springer; 1997. p. 585-602.

60. Brown MR, Jeffrey SW, Volkman JK and Dunstan GA. Nutritional properties of microalgae for mariculture. Aquaculture 1997;151:315-331.

61. Dore JE, Cysewski GR. Haematococcus algae meal as a source of natural astaxanthin for aquaculture feeds. Cyanotech. Corpor. 2003;1-5.

62. Lum KK, Kim J, Lei XG. Dual potential of microalgae as a sustainable biofuel feedstock and animal feed. J. Animal Sci. Biotechnol. 2013;4:1-7.

63. Yaakob Z, Ali E, Zainal A, Mohamad M, Takriff MS. An overview: Biomolecules from microalgae for animal feed and aquaculture. J. Biol. Res. (Thessalon.) 2014;21:1-10.

64. Toyomizu M, Sato K, Taroda H, Kato T, Akiba Y. Effects 
of dietary Spirulina on meat colour in muscle of broiler chickens. Brit. Poult. Sci. 2001;42:197-202.

65. Amotz B. Industrial production of microalagal cell-mass and secondary products - Major industrial species Dunaliella. Handbook of microalgal culture biotechnology and applied phycology. BlackWell Publishing Limited, UK; 2004. p. 273-280.

66. Bruneel C, Lemahieu C, Fraeye I, et al. Impact of microalgal feed supplementation on omega-3 fatty acid enrichment of hen eggs. J. Funct. Foods 2013;5:897-904.

67. Evans A, Smith D, Moritz J. Effects of algae incorporation into broiler starter diet formulations on nutrient digestibility and 3 to $21 \mathrm{~d}$ bird performance. J. Appl. Poult. Res. 2015;24:206-214.

68. Shanmugapriya B, Babu SS, Hariharan T, Sivaneswaran S, Anusha M. Dietary administration of Spirulina platensis as probiotics on growth performance and histopathology in broiler chicks. Int. J. Rec. Sci. Res. 2015;6:2650-2653.

69. Zahroojian N, Moravej H, Shivazad M. Effects of dietary marine algae (Spirulina platensis) on egg quality and production performance of laying hens. J. Agr. Sci. Technol. 2013;15:1353-1360.

70. Kang H, Salim H, Akter N, et al. Effect of various forms of dietary Chlorella supplementation on growth performance, immune characteristics, and intestinal microflora population of broiler chickens. J. Appl. Poult. Res. 2013;22:100-108.

71. Zheng L, Oh ST, Jeon JY, et al. The dietary effects of fermented Chlorella vulgaris $\left(\mathrm{CBT}^{\circledR}\right.$ ) on production performance, liver lipids and intestinal microflora in laying hens. Asian-Australas J. Anim. Sci. 2012;25:261-266.

72. Kotrbáček V, Skřivan M, Kopecký J, et al. Retention of carotenoids in egg yolks of laying hens supplemented with heterotrophic Chlorella. Czech J. Anim. Sci. 2013;58:193-200.

73. Lemahieu C, Bruneel C, Termote-Verhalle R, Muylaert K, Buyse J, Foubert I. Impact of feed supplementation with different omega-3 rich microalgae species on enrichment of eggs of laying hens. Food Chem. 2013;141:4051-4059.

74. Harel M, Clayton D, Bullis R. Feed formulation for terrestrial and aquatic animals. Patent Pub. No. US 2007/0082008 A1. 2004.

75. Arora N, Agarwal S, Murthy R. Latest technology advances in cosmaceuticals. Int. J. Pharm. Sci. Drug Res. 2012;4: 168-182.

76. Wang HMD, Chen CC, Huynh P, Chang JS. Exploring the potential of using algae in cosmetics. Bioresour. Technol. 2015;184:355-362.

77. Fabrowska J, Łęska B, Schroeder G, Messyasz B, Pikosz M. Biomass and extracts of algae as material for cosmetics. In: Kim SK, Chojnacka K, eds. Marine algae extracts. 1st ed. Wiley-VCH Verlag GmbH \& Co. KGaA; 2015. p. 681-706.

78. Azmir J, Zaidul ISM, Rahman MM, Sharif KM, et al. Techniques for extraction of bioactive compounds from plant materials: A review. J. Food Eng. 2013;117:426-436.

79. Wang HM, Chen CY, Wen ZH. Identifying melanogenesis inhibitors from Cinnamomum subavenium with in vitro and in vivo screening systems by targeting the human tyrosinase. Exp. Dermatol. 2011;20:242-248.
80. Thomas NV, Kim SK. Beneficial effects of marine algal compounds in cosmeceuticals. Mar. Drugs 2013;11:146-164.

81. Aditya T, Bitu G, Eleanor MG. The role of algae in pharmaceutical development. J. Pharm. Nanotechnol. 2016;4:82-89.

82. Ariede MB, Candido TM, Jacome ALM, Velasco MVR, de Carvalho JCM, Baby AR. Cosmetic attributes of algae - A review. Algal Res. 2017;25:483-487.

83. Abedin RM, Taha HM. Antibacterial and antifungal activity of cyanobacteria and green microalgae. Evaluation of medium components by Plackett-Burman design for antimicrobial activity of Spirulina platensis. Glo. J. Biotechnol. Biochem. 2008;3:22-31.

84. Herrero M, Castro-Puyana M, Mendiola JA, Ibañez E. Compressed fluids for the extraction of bioactive compounds. Trends Anal. Chem. 2013;43:67-83.

85. Yan N, Fan C, Chen Y, Hu Z. The potential for microalgae as bioreactors to produce pharmaceuticals. Int. J. Mol. Sci. 2016;17:1-24.

86. Scaife MA, Nguyen J, Rico D, Lambert K, Helliwell E, Smith AG. Establishing Chlamydomonas reinhardtii as an industrial biotechnology host. Plant J. 2015;82:532-546.

87. Skjånes K, Rebours C, Lindblad P. Potential for green microalgae to produce hydrogen, pharmaceuticals and other high value products in a combined process. Crit. Rev. Biotechnol. 2013;33:172-215

88. Bhattacharjee M. Pharmaceutically valuable bioactive compounds of algae. Asian J. Pharm. Clin. Res. 2016;9:43-47.

89. Santhosh S, Dhandapani R, Hemalatha N. Bioactive compounds from microalgae and its different applications - A review. Adv. Appl. Sci. Res. 2016;7:153-158.

90. Gouveia L. Microalgae as a feedstock for biofuels. 1st ed. Springer; 2011. p. 1-69.

91. Wen Z, Johnson MB. Microalgae as a feedstock for biofuel production. Virginia Cooperative Extension publ. 442-880. Virginia, PA: Virginia Polytechnic Institute and State University; 2009.

92. Wang $\mathrm{B}, \mathrm{Li} \mathrm{Y}, \mathrm{Wu} \mathrm{N}$, Lan CQ. $\mathrm{CO}_{2}$ bio-mitigation using microalgae. Appl. Microbiol. Biotechnol. 2008;79:707-718.

93. Mondal M, Goswami S, Ghosh A, et al. Production of biodiesel from microalgae through biological carbon capture: A review. 3 Biotech 2017;7:1-21.

94. Chader S, Mahmah B, Chetehouna K, Mignolet E. Biodiesel production using Chlorella sorokiniana a green microalga. Revue Energ. Renouv. 2011;14:21-26.

95. Kim GV, Choi W, Kang D, Lee S, Lee H. Enhancement of biodiesel production from marine alga, Scenedesmus sp. through in situ transesterification process associated with acidic catalyst. BioMed Res. Int. 2014;2014:391542.

96. Mata M, Melo A, Meireles S, Mendes A, Martins A, Caetano N. Potential of microalgae Scenedesmus obliquus grown in brewery wastewater for biodiesel production. Chem. Eng. Trans. 2013;32:901-906.

97. Moser BR. Biodiesel production, properties, and feedstocks. In Vitro Cell. Dev. Biol. Plant 2009;45:229-266.

98. Shah GC, Yadav M, Tiwari A. Assessment for the higher production of biodiesel from Scenedesmus dimorphus algal species using different methods. J. Biofuels 2011;2:91-97. 
99. Shin DY, Cho HU, Utomo JC, Choi YN, Xu X, Park JM. Biodiesel production from Scenedesmus bijuga grown in anaerobically digested food wastewater effluent. Bioresour. Technol. 2015;184:215-221.

100. Jena J, Nayak M, Panda HS, et al. Microalgae of Odisha coast as a potential source for biodiesel production. World Environ. 2012;2:11-16.

101. Unpaprom Y, Tipnee S, Ramaraj R. Biodiesel from green alga Scenedesmus acuminatus. Int. J. Sust. Green Energ. 2015;4:1-6.

102 Shenbaga Devi A, Santhanam P, Rekha V, et al. Culture and biofuel producing efficacy of marine microalgae Dunaliella salina and Nannochloropsis sp. J. Algal Biomass Utln. 2012;3:38-44.

103. Eman MF, El DM. Fatty acids composition and biodiesel characterization of Dunaliella salina. J. Water Resour. Prot. 2013;5:894-899.

104. Abd El Baky HH, El-Baroty GS, Bouaid A. Lipid induction in Dunaliella salina culture aerated with various levels $\mathrm{CO}_{2}$ and its biodiesel production. J. Aquacult. Res. Dev. 2014;5:1-6.

105. Srinivasakumar K. Biodiesel fuel production from marine microalgae Isochrysis galbana, Pavlova lutheri, Dunaliella salina and measurement of its viscosity and density. Int. J. Mar. Sci. 2013;3:33-35.

106. Weldy CS, Huesemann M. Lipid production by Dunaliella salina in batch culture: Effects of nitrogen limitation and light intensity. J. Undergraduate Res. 2007;7:115-122.

107. Ma Y, Wang Z, Yu C, Yin Y, Zhou G. Evaluation of the potential of 9 Nannochloropsis strains for biodiesel production. Bioresour. Technol. 2014;167:503-509.

108. Sohi SMH, Eghdami A. Biodiesel production using marine microalgae Dunaliella salina. J. Biodivers. Environ. Sci. 2014;4:177-182.

109. Chisti Y. Biodiesel from microalgae. Biotechnol. Adv. 2007;25:294-306.

110. Hariskos I, Posten C. Biorefinery of microalgae Opportunities and constraints for different production scenarios. Biotechnol. J. 2014;9:739-752.

111. Chew KW, Yap JY, Show PL, et al. Microalgae biorefinery: High value products perspectives. Bioresour. Technol. 2017;229:53-62.

112. Nagarajan D, Lee DJ, Kondo A, Chang AS. Recent insights into biohydrogen production by microalgae - From biophotolysis to dark fermentation. Bioresour. Technol. 2017;227:373-387.

113. Benemann JR. Hydrogen production by microalgae. J. Appl. Phycol. 2000;12:291-300.

114. Shaishav S, Singh R, Satyendra T. Biohydrogen from algae: Fuel of the future. Int. Res. J. Environ. Sci. 2013;2:44-47.

115. Saifuddin N, Priatharsini P. Developments in bio-hydrogen production from algae: A review. Res. J. Appl. Sci. Eng. Technol. 2016;12:968-982.

116. Amaro HM, Esquível MG, Pinto TS, Malcata FX. Hydrogen production by microalgae. In: Reza Razeghifard, ed. Natural and artificial photosynthesis: Solar power as an energy source. 1st ed. John Wiley and Sons, Inc.; 2013. p. 231-241.
117. Chader S, Mahmah B, Chetehouna K, Amrouche F, Abdeladim K. Biohydrogen production using green microalgae as an approach to operate a small proton exchange membrane fuel cell. Int. J. Hydrogen Energ. 2011;36:4089-4093.

118. Ali I, Rakshit SK, Kanhayuwa L. Biohydrogen production from microalgae of Chlorella sp. In: The International Conference on Sustainable Community Development; 27-29 January 2011; p.74-77.

119. Guan Y, Deng M, Yu X, Zhang W. Two-stage photo-biological production of hydrogen by marine green alga Platymonas subcordiformis. Biochem. Eng. J. 2004;19:69-73.

120. Kumari S, Nasr M, Kumar S. Technological advances in biohydrogen production from microalgae. In: Gupta SK, Malik A, Bux F, eds. Algal biofuels: Recent advances and future prospects. Durban: Springer International Publishing; 2017. p. 347-360.

121. Chiaramonti D. Bioethanol: Role and production technologies. In: Ranalli P, ed. Improvement of crop plants for industrial end uses. 1st ed. Netherlands: Dordrecht: Springer; 2007. p. 209-251.

122. Harun R, Danquah MK, Forde GM. Microalgal biomass as a fermentation feedstock for bioethanol production. J. Chem. Technol. Biotechnol. 2010;85:199-203.

123. Nigam PS, Singh A. Production of liquid biofuels from renewable resources. Prog. Energ. Combust. Sci. 2011;37:52-68.

124. Hirano A, Ueda R, Hirayama S, Ogushi Y. $\mathrm{CO}_{2}$ fixation and ethanol production with microalgal photosynthesis and intracellular anaerobic fermentation. Energy 1997;22:137-142.

125. Ueno Y, Kurano N, Miyachi S. Ethanol production by dark fermentation in the marine green alga, Chlorococcum littorale. J. Ferment. Bioeng. 1998;86:38-43.

126. Hirayama S, Ueda R, Ogushi Y, et al. Ethanol production from carbon dioxide by fermentative microalgae. Stud. Surf. Sci. Catal. 1998;114:657-660.

127. Ho SH, Li PJ, Liu CC, Chang JS. Bioprocess development on microalgae-based $\mathrm{CO}_{2}$ fixation and bioethanol production using Scenedesmus obliquus CNW-N. Bioresour. Technol. 2013;145:142-149.

128. Harun R, Danquah MK. Influence of acid pre-treatment on microalgal biomass for bioethanol production. Process Biochem. 2011;46:304-309.

129. Markou G, Angelidaki I, Nerantzis E, Georgakakis D. Bioethanol production by carbohydrate-enriched biomass of Arthrospira (Spirulina) platensis. Energies 2013;6:3937-3950.

130. John RP, Anisha GS, Nampoothiri KM, Pandey A. Micro and macroalgal biomass: A renewable source for bioethanol. Bioresour. Technol. 2011;102:186-193.

131. Anand P, Tiwari A, Mishra RM, Awasthi S. Production of algae biofertilizers for rice crop (Oryza sativa) to safe human health \& environment as a supplement to the chemical fertilizers. J. Sci. 2015;5:13-15

132. Abdel-Raouf N, Al-Homaidan A, Ibraheem I. Agricultural importance of algae. Afr. J. Biotechnol. 2012;11:11648-11658.

133. Song T, Mårtensson L, Eriksson T, Zheng W, Rasmussen U. Biodiversity and seasonal variation of the cyanobacterial assemblage in a rice paddy field in Fujian, China. FEMS Microbiol. Ecol. 2005;54:131-140. 
134. Garcia-Gonzalez J, Sommerfeld M. Biofertilizer and biostimulant properties of the microalga Acutodesmus dimorphus. J. Appl. Phycol. 2016;28:1051-1061.

135. Faheed FA, Fattah ZA. Effect of Chlorella vulgaris as bio-fertilizer on growth parameters and metabolic aspects of lettuce plant. J. Agr. Soc. Sci. (Pak.). 2008;4:165-169.

136. Renuka N, Prasanna R, Sood A, et al. Exploring the efficacy of wastewater-grown microalgal biomass as a biofertilizer for wheat. Environ. Sci. Pollut. Res. 2016;23:6608-6620.

137. Dineshkumar R, Subramanian J, Gopalsamy J, et al. The impact of using microalgae as biofertilizer in maize (Zea mays L.). Waste Biomass Valori. 2017:1-10.

138. González-Delgado ÁD, Kafarov V. Microalgae based biorefinery: Issues to consider. C.T.F Cienc. Tecnol. Futuro 2011;4:5-22. 